\title{
Prevalence, types, and malformations in congenital anomalies of the kidney and urinary tract in newborns: a retrospective hospital-based study
}

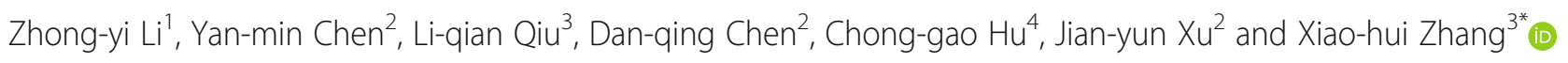

\begin{abstract}
Background: Congenital anomalies of the kidney and urinary tract (CAKUTs) are some of the most common birth defects affecting newborns. CAKUTs often have poor birth outcomes owing to the limited experience of physicians in developing countries regarding antenatal and postnatal diagnosis. We aimed to estimate the epidemiology of CAKUTs using data from a hospital-based registry in Zhejiang Province, China.

Methods: We included a total of 2790 newborns with CAKUTs, identified among 1,748,038 births during 20102016. The prevalence and type of CAKUTs, maternal and neonatal characteristics, and associated malformations were analyzed.

Results: The average prevalence of CAKUTs born to mothers overall and mothers aged $\geq 35$ years were both around 1.60 per 1000 births (95\% confidence interval $(\mathrm{Cl}), 1.54-1.66$; $95 \% \mathrm{Cl}, 1.44-1.83$, respectively) during the study period. The prevalence of CAKUTs changed over time among all women and women of advanced maternal age, although no significant trends were observed. CAKUTs were more likely to occur in male than female newborns (odds ratio (OR) 1.28, 95\% Cl 1.18-1.38), in multiple births than singletons (OR 1.53, 95\% Cl 1.21-1.92) and in urban areas than rural areas (OR 1.27,95\% Cl 1.18-1.37). The overall prenatal detection rate of CAKUTs was 73. $87 \%$. The average gestational age at antenatal diagnosis was $26.57 \pm 8.70$ weeks. A total $22.69 \%$ CAKUTs had associated malformations. Congenital heart defects were the most common anomalies, accounting for $8.89 \%$ of the whole population. The main proportion in subgroups was hydronephrosis, representing $31.79 \%$ of registered CAKUTS.

Conclusions: There was a nearly twofold increase in the prevalence of CAKUTs from 2010 to 2016 in Zhejiang Province. CAKUTs are strongly associated with male sex, multiple births, urban areas, and other nonurinary congenital malformations.
\end{abstract}

Keywords: Congenital anomalies of the kidney and urinary tract (CAKUTs), Prevalence, Associated malformations, Prenatal detection

\footnotetext{
* Correspondence: zjfb_amy@zju.edu.cn

32Department of Women's Health, Women's Hospital, Zhejiang University

School of Medicine, No.1 Xueshi Road, Hangzhou, Zhejiang Province 310006,

People's Republic of China

Full list of author information is available at the end of the article
}

(c) The Author(s). 2019 Open Access This article is distributed under the terms of the Creative Commons Attribution 4.0 International License (http://creativecommons.org/licenses/by/4.0/), which permits unrestricted use, distribution, and reproduction in any medium, provided you give appropriate credit to the original author(s) and the source, provide a link to the Creative Commons license, and indicate if changes were made. The Creative Commons Public Domain Dedication waiver (http://creativecommons.org/publicdomain/zero/1.0/) applies to the data made available in this article, unless otherwise stated. 


\section{Background}

Congenital anomalies of the kidney and urinary tract (CAKUTs) are some of the most common birth defects in newborns. CAKUTs include a broad spectrum of structural and functional abnormalities of the kidney, collecting system, bladder, and urethral abnormalities. The prevalence of CAKUTs ranges from 4.2 per 10,000 births in Taiwan to 4.0 per 1000 births in Russia and some Asian and European countries [1-5]. Over half of pregnancies involving severe CAKUTs have adverse birth outcomes, such as stillbirth or even spontaneous abortion [6]. Among live births, CAKUTs are closely associated with impaired renal function, particularly chronic kidney and kidney-related diseases in young adults [7-10]. For example, approximately $39.8 \%$ of end-stage renal disease cases in patients younger than 20 years old in Japan are owing to CAKUTs [9]. Additionally, CAKUTs are likely to be associated with malfunctions in other organs $[5,11]$. Owing to improvement in antenatal diagnostic technologies, most CAKUTs can be identified and classified at an early stage of pregnancy using ultrasonography, radiation, computed tomography $(\mathrm{CT})$, magnetic resonance imaging (MRI), and new genetic approaches [5, 12-15].

China has seen few comprehensive evaluations of CAKUTs in newborns. A previous study covering 264 patients showed that $43.9 \%$ of chronic kidney disease (CKD) cases in children were owing to CAKUTs [16]. Owing to the poor outcomes of CKD in children and the huge population in China, it is necessary to have an accurate estimate of CAKUTs $[9,16,17]$. Zhejiang Province is located on the eastern coast of China, where a provincial birth defect surveillance system has been established for over 30 years. This provides a valuable platform for scientific research on CAKUTs.

This study aimed to evaluate the epidemiology of CAKUTs using data from a hospital-based birth defect surveillance system in this province. To the best of our knowledge, this is the first work to give full consideration to this topic at provincial level. Our findings may be beneficial for clinical guidance and policy making.

\section{Methods}

\section{Study design and data sources}

This was a retrospective study based on data from a birth defect surveillance system in China's Zhejiang Province. In this study, participants included all births and all ascertained patients with CAKUTs registered in the system from 2010 to 2016.

The birth defect surveillance system in Zhejiang Province is a hospital-based registry system covering 91 delivery hospitals. The average number of births per year recorded in the system represents about 30\% of total births in this province. The registry contains information from clinical records and routine antenatal care facilities. The data include maternal characteristics, malformation subtypes, pregnancy outcomes, and newborn birth records. Here, we collected information of all births, including early fetal loss, live births, and stillbirths after at least 28 weeks of gestation. Cases with anomalies were assessed by experts within 7 days of delivery. Regardless of gestational weeks and pregnancy outcomes, all anomalies were reported online by well-trained medical staff. Quality control was strictly carried out by physicians in surveillance hospitals and the Women's Hospital, School of Medicine Zhejiang University throughout this work.

The Committee for Research Ethics at Zhejiang Provincial Center for Disease Control and Prevention approved the study (number: 2018KY036). All information was confidential.

\section{Antenatal care and CAKUTs identification}

In China, all pregnant women are required to make $7-$ 11 antenatal visits during the course of their pregnancy, at gestational ages $6-13,14-19,20-24,25-28,29-32$, 33-36, and 37-41 weeks. Women with pronounced risk factors, such as advanced maternal age, previous adverse pregnancy outcomes, specific complications, or abnormal family history, are encouraged to make additional prenatal visits.

Normally, maternal serum screening is recommended in the first and second trimesters. Similarly, ultrasound is offered for nuchal translucency screening at 11-13 weeks of gestation. At 20-24 weeks of gestation, systematic prenatal ultrasound screening is recommended, to confirm the presence or absence of most malformations. Noninvasive prenatal testing has been used since 2013 and is offered to eligible women at 12-22 weeks of gestation. When necessary, amniocentesis and chorionic villous sampling are usually conducted at 16-20 weeks of gestation. Radiation, CT, MRI, and genetic testing are also used to confirm anomalies. Autopsies can be helpful, but they are not widely performed.

With respect to CAKUTs screening, all fetuses undergo routine ultrasound scans. In this study, diagnoses of CAKUTs were made by obstetricians and pediatricians. CAKUTs were classified according to the International Statistical Classification of Diseases and Related Health Problems 10th Revision (ICD-10), codes Q60-Q64. Furthermore, postnatal examination was suggested for suspected prenatal anomalies. Fetuses with unconfirmed defects were not reported. Here, a diagnosis of hydronephrosis was made when the maximum diameter of the renal pelvis was $\geq 10 \mathrm{~mm}$ on a prenatal ultrasound scan after 30 weeks of gestation. 


\section{Statistical analysis}

The prevalence of CAKUTs was calculated as the number of cases per 1000 births, including early fetal loss, live birth, and fetal death at or after the 28th week of gestation. Cases with associated malformations were only counted as one case when we presented overall prevalence. However, these cases were allocated to different subgroups and counted separately.

The chi-square test was used to compare the changes in prevalence of CAKUTs among all women and among women with advanced age. Odds ratios (ORs) and 95\% confidence intervals (CIs) were used to explore the associations of CAKUTs with maternal characteristics and birth outcomes. The proportion of each subgroup of CAKUTs and associated malformations were presented. All $P$-values were two-tailed and values below 0.05 were considered significant. SPSS 19.0 software (SPSS Inc., Chicago, IL, USA) was used for data analysis.

\section{Results}

\section{Trends in the prevalence of CAKUTs}

There were 2790 CAKUTs identified among 1,748,038 births during 2010-2016, yielding an average prevalence of 1.60 per 1000 births (95\% CI, 1.54-1.66). Among births to women aged $\geq 35$ years, the prevalence of CAKUTs was 1.63 per 1000 births (95\% CI, 1.44-1.83). The prevalence of CAKUTs changed over time among all women and women with advanced age, despite no significant linear trends (Table 1).

\section{Maternal characteristics and birth outcomes in CAKUTs}

Table 2 shows maternal characteristics and birth outcomes in CAKUTs. Among 2790 patients with CAKUTs, the number and proportion of males, females, and births with unclear sex were 1583 (56.73\%), 1096 (39.28\%), and
111 (3.98\%), respectively. Males had a higher risk of CAKUTs (OR 1.28, 95\% CI 1.18-1.38) than females. The sex ratio was 1.44:1. Further, multiple births and births in urban areas presented a higher risk of CAKUTs than singletons (OR 1.53, 95\% CI 1.21-1.92) and births in rural areas (OR 1.27, 95\% CI 1.18-1.37). CAKUTs were poorly associated with maternal age. A total 2061 cases with CAKUTs were recognized prenatally, yielding a prenatal detection rate of $73.87 \%$. The average gestational age at antenatal diagnosis was $26.57 \pm 8.70$ weeks.

\section{Subtypes of CAKUTs and associated malformations}

Overall, $22.69 \%$ of births with CAKUTs had associated malformations; in male and female newborns, the corresponding proportion was 20.34 and $21.90 \%$, respectively. The most common coexisting anomalies were congenital heart defects, accounting for $8.89 \%$ of all registered cases. Most associated malformations were reported more frequently in male than in female newborns.

The most frequent CAKUT was hydronephrosis, representing $31.79 \%$ of all CAKUTs. This was followed by other CAKUTs, polycystic kidney, renal agenesis, renal ectopia, and renal duplication (Table 3).

\section{Discussion}

In this study, the prevalence of CAKUTs was 1.60 per 1000 births, with 95\% CI 1.54-1.66. This rate is much lower than in reports from Copenhagen University Hospital, Murmansk County in Russia, and western areas of Saudi Arabia, where the corresponding data were around 3-4 cases per 1000 births; however, our finding is far higher than that in Taiwan (4.2 per 10,000 births), and similar to that in Hunan, China (11.7 per 10,000 births) $[1-4,18,19]$. Such inconsistencies could be explained by differences in sociodemographic background, malformation inclusion criteria,

Table 1 Prevalence trends of congenital anomalies of the kidney and urinary tract (CAKUTs) among total and women aged $\geq 35$ years

\begin{tabular}{|c|c|c|c|c|c|c|}
\hline \multirow[t]{2}{*}{ Time } & \multicolumn{3}{|c|}{ Born to all women } & \multicolumn{3}{|c|}{ Born to women aged $\geq 35$ years } \\
\hline & $\begin{array}{l}\text { Number } \\
\text { of births }\end{array}$ & $\begin{array}{l}\text { Number of cases } \\
\text { of CAKUTs }\end{array}$ & $\begin{array}{l}\text { Prevalence } \\
\text { per } 1000 \text { births }\end{array}$ & $\begin{array}{l}\text { Number } \\
\text { of births }\end{array}$ & $\begin{array}{l}\text { Number of cases } \\
\text { of CAKUTs }\end{array}$ & $\begin{array}{l}\text { Prevalence } \\
\text { per } 1000 \text { births }\end{array}$ \\
\hline 2010 & 200,008 & 217 & 1.08 & 22,539 & 14 & 0.62 \\
\hline 2011 & 221,469 & 229 & 1.03 & 19,557 & 18 & 0.92 \\
\hline 2012 & 253,540 & 428 & 1.69 & 22,397 & 44 & 1.96 \\
\hline 2013 & 266,036 & 432 & 1.62 & 22,627 & 47 & 2.08 \\
\hline 2014 & 265,289 & 431 & 1.62 & 23,635 & 36 & 1.52 \\
\hline 2015 & 264,029 & 474 & 1.80 & 26,608 & 52 & 1.95 \\
\hline 2016 & 277,667 & 579 & 2.09 & 29,345 & 61 & 2.08 \\
\hline \multirow[t]{3}{*}{ average } & $1,748,038$ & 2790 & 1.60 & 166,708 & 272 & 1.63 \\
\hline & & \multicolumn{2}{|l|}{$x^{2}=126.57$} & & \multicolumn{2}{|l|}{$x^{2}=29.96$} \\
\hline & & \multicolumn{2}{|l|}{$P<0.001$} & & \multicolumn{2}{|l|}{$P<0.001$} \\
\hline
\end{tabular}


Table 2 Maternal characteristics and birth outcomes in CAKUTs

\begin{tabular}{|c|c|c|c|c|}
\hline Variable & Total births & Number of cases of CAKUTs & Prevalence per 1000 births & OR 95\% Cl \\
\hline \multicolumn{5}{|l|}{ Infant gender } \\
\hline Male & 917,758 & 1583 & 1.72 & $1.28(1.18-1.38)^{*}$ \\
\hline Female & 818,510 & 1096 & 1.34 & Ref \\
\hline \multicolumn{5}{|l|}{ Maternal age } \\
\hline$<20$ & 48,776 & 52 & 1.06 & $0.65(0.50-0.86)^{* *}$ \\
\hline $20-$ & 396,705 & 574 & 1.45 & $0.89(0.80-0.99)^{* * *}$ \\
\hline $25-$ & 761,274 & 1243 & 1.63 & Ref \\
\hline $30-$ & 374,560 & 650 & 1.74 & $1.06(0.97-1.17)$ \\
\hline$\geq 35$ & 166,708 & 271 & 1.63 & $1.00(0.87-1.14)$ \\
\hline Multiple births & 31,121 & 75 & 2.41 & $1.53(1.21-1.92)^{*}$ \\
\hline Single birth & $1,716,902$ & 2715 & 1.58 & Ref \\
\hline \multicolumn{5}{|l|}{ Region } \\
\hline Urban & 875,763 & 1562 & 1.78 & $1.27(1.18-1.37)^{*}$ \\
\hline Rural & 872,275 & 1228 & 1.41 & Ref \\
\hline
\end{tabular}

Abbreviations: CAKUTS congenital anomalies of the kidney and urinary tract, $O R$ odds ratio, $C l$ confidence interval ${ }^{*} P<0.001{ }^{*} P=0.002{ }^{* *} P=0.016$

study population, diagnostic technology and surveillance quality. In Murmansk County, a population-based birth registry recorded anomalies diagnosed from 22 weeks of gestation to hospital discharge [1]. Those authors admitted that some figures had been overestimated owing to the lack of strict diagnostic criteria for pyelectasis, hydronephrosis, and unspecified anomalies [1]. In Saudi Arabia, the high rate of consanguineous marriage within the local population might increase the rate of CAKUTs [2]. The study in Denmark followed up a birth cohort for 8 years [3]. In our study, the prevalence might be underestimated because all anomalies were restricted to within 7 days after birth, similar to the study in Taiwan [4]. Longitudinal postnatal follow-up is recommended, as some malformations might be revealed later in life. Finally, this wide interval of CAKUTs prevalence could be owing to the currently limited literature.

Table 3 Associated anomalies and distribution of CAKUTs, by sex

\begin{tabular}{|c|c|c|c|c|c|c|c|}
\hline \multirow[t]{2}{*}{ Subtype } & \multicolumn{2}{|c|}{ Total (2790) } & \multicolumn{2}{|c|}{ Male (1583) } & \multicolumn{2}{|c|}{ Female (1096) } & \multirow{2}{*}{$\begin{array}{l}\text { Male/ } \\
\text { Female }\end{array}$} \\
\hline & $\bar{n}$ & $\%$ & $\bar{n}$ & $\%$ & $\bar{n}$ & $\%$ & \\
\hline Associated anomalies & 633 & 22.69 & 322 & 20.34 & 240 & 21.90 & 1.34 \\
\hline \multicolumn{8}{|l|}{ Subtypes } \\
\hline Congenital heart defects & 248 & 8.89 & 129 & 8.15 & 97 & 8.85 & 1.33 \\
\hline Limb defects & 56 & 2.01 & 30 & 1.90 & 17 & 1.55 & 1.76 \\
\hline Neural tube defect & 19 & 0.68 & 7 & 0.44 & 7 & 0.64 & 1.00 \\
\hline Hydrocephalus & 16 & 0.57 & 7 & 0.44 & 6 & 0.55 & 1.17 \\
\hline Trisomy 21 & 6 & 0.22 & 6 & 0.38 & 0 & 0.00 & - \\
\hline Pcromphalus & 9 & 0.32 & 7 & 0.44 & 1 & 0.09 & 7.00 \\
\hline Diaphragmatocel & 5 & 0.18 & 3 & 0.19 & 1 & 0.09 & 3.00 \\
\hline Cheilopalatognathus & 16 & 0.57 & 5 & 0.32 & 9 & 0.82 & 0.56 \\
\hline Other & 368 & 13.19 & 176 & 11.12 & 141 & 12.86 & 1.25 \\
\hline \multicolumn{8}{|l|}{ Subtypes of CAKUTs } \\
\hline Hydronephrosis & 890 & 31.90 & 666 & 42.07 & 207 & 18.89 & 3.22 \\
\hline Polycystic kidney & 533 & 19.10 & 245 & 15.48 & 258 & 23.54 & 0.95 \\
\hline Renal agenesis & 529 & 18.96 & 241 & 15.22 & 270 & 24.64 & 0.89 \\
\hline Renal ectopia & 121 & 4.34 & 59 & 3.73 & 61 & 5.57 & 0.97 \\
\hline Renal duplication & 67 & 2.40 & 32 & 2.02 & 35 & 3.19 & 0.91 \\
\hline Others & 678 & 24.30 & 349 & 22.05 & 281 & 25.64 & 1.24 \\
\hline
\end{tabular}


In our study, the prevalence of CAKUTs doubled from 2010 to 2016. Rising rates of CAKUTs have also been observed in parts of Europe and in Korea but were not reported in studies performed in Murmansk County of Russia and Taiwan [1, 4, 20-23]. The increasing prevalence might be owing to increased screening, developments in ultrasound technology, and improved birth defect surveillance in our study. The upward trend in prevalence of CAKUTs in Europe agrees with this view $[22,23]$. The underlying cause of CAKUTs and related risk factors should be fully considered to reflect the true increase in prevalence. To our knowledge, CAKUTs are caused by genetic modifications in the kidney that are related to development, and as a result of exposure to drugs or fetal environmental factors, as indicated in mouse models and models of developmental diseases in humans [14, 24, 25]. Maternal obesity, fertility treatments, multiparity, infectious diseases, and diabetes during pregnancy could increase the occurrence of CAKUTs [1, 4, 26, 27]. In 2014, the Chinese government initiated a policy encouraging people to have a second child. The proportion of pregnant women with advanced age and who have complications has been on rise. This might partly explain the increase in the rate of CAKUTs found in our study.

In the present study, a high proportion of CAKUTs was reported in male newborns, newborns from multiple births, and newborns from urban areas. A population-based case-control study in Taiwan showed that males had a 1.83-fold greater risk of CAKUTs than females [4]. A clear male predominance in CAKUTs has been documented in numerous studies. The sex ratio of CAKUTs is around 2:1-3:1, which includes patients who undergo postnatal follow-up [2, 7]. In reports from Saudi Arabia, about $66 \%$ of cases were male; however, it excluded cases of CAKUTs at less than 20 gestational weeks [2]. In our study, the sex in about $4 \%$ of CAKUTs was unknown because we included early fetal loss. This proportion was larger than the corresponding data in Taiwan and Saudi Arabia (less than or around 2\%) [2, 4]. Nevertheless, the sex ratio of CAKUTs in our study was comparable to a national survey of children with end-stage renal disease in China [17] Sex-specific mechanisms should be investigated with respect to environmental stress, the renal transcriptome, and gene expression and pathways.

A rising rate of multiple births in Zhejiang Province has been previously reported [28]. With socioeconomic development, delaying childbirth has become popular among women in China. The increasing proportion of women with advanced reproductive age has been strongly linked to the increasing use of assisted reproductive technology. Both fertility treatments and multiple births might increase the risk of birth defects, including urogenital system abnormalities [29-31]. In our study, the prevalence of CAKUTs differed obviously by region. Similarly, urban areas of China showed higher prevalence of congenital heart defects in Hunan, and higher overall prevalence of birth defects in Dalian city $[19,32]$. This could be attributed to greater awareness of health care among women in urban areas, which promotes better utilization of antenatal care. Likewise, women residing in urban areas face greater risks from environmental exposures that could lead to malformations. We found poor associations between maternal age and CAKUTs, which was supported by the Murmansk County Birth Registry Study [1]. However, in Taiwan, advanced maternal age increased the risk of CAKUTs [4]. Nevertheless, among nonchromosomal anomalies, maternal age was also linked with CAKUTs to some extent, but with a smaller effect than chromosomal anomalies [21]. The proportion of CAKUTs associated with chromosomal anomalies was also lower in our study.

It has been reported that $6-50 \%$ of CAKUTs are associated with malformations $[1-3,11,25,26]$. The proportion of non-isolated anomalies in our study was relatively low, which could be owing to a relatively low prevalence of CAKUTs. Among 1678 CAKUT cases in northeastern France with 2 years' follow-up, 34\% had associated malformations [11]. Variability in the length of follow-up and study population should be taken into account. Our results showed congenital heart defects to be the most common anomalies associated with CAKUTs, followed by abnormalities of the limbs. Congenital heart defects are the leading malformations in Zhejiang Province. It has also been reported that CAKUTs are one of the most common defects associated with congenital heart defects [33, 34]. According to published studies, the most frequently reported nonurinary anomalies involve the genitourinary tract; central nervous system, musculoskeletal, digestive and cardiovascular systems, and chromosomal anomalies $[2,5,11]$.

In our study, the most frequently detected subgroup of CAKUTs was hydronephrosis, similar to most reports $[1-3,11]$. However, the distribution of hydronephrosis showed some differences across studies. In Saudi Arabia, over $50 \%$ of CAKUTs were hydronephrosis; in northeastern France and Murmansk County, hydronephrosis accounted for 28.9 and $14.3 \%$ of CAKUTs, respectively $[1,2,11]$. These results depend largely on variation in the diagnostic criteria and study population. As noted, in the study from Saudi Arabia, mild hydronephrosis was defined as maximum diameter $5-10 \mathrm{~mm}$ whereas in Murmansk, multiple births were excluded $[1,2]$. In those reports, unspecified malformations were less commonly reported because some cases were not confirmed after discharge; this proportion was lower in our study than in Murmansk, where half of malformations were 
other CAKUTs [1]. The prenatal detection rate of CAKUTs in our study was higher than that recorded in the Murmansk County Birth Registry Study (42.1\%), similar to the rate in northeastern of France (71\%), but lower than the level in the Netherlands (over 80\%) [11, 22]. In the Netherlands, this was mainly attributable to a large proportion of anomalies of the collecting system (70.4\%) and high coverage of prenatal screening. The average term at prenatal diagnosis in our study was similar to the study in France (26.6 \pm 9.2 weeks) [5].

A strength of the current work is that we used provincial data, to provide a more thorough understanding of the epidemiology of CAKUTs. The most important strength of this study is the large sample size covering over 1.5 million births, which yielded reliable results. However, the potential limitations of this work should also be mentioned. First, the diagnosis of CAKUTs was confirmed within 7 days of birth but before the child was discharged from the hospital. This may have had some negative influence on comparisons with developed countries that maintain universal population-based registries and conduct long-term observation. Second, misclassification can not be disregarded in the higher proportion of unspecified anomalies, accounting for $24.3 \%$ of CAKUTs. Lastly, there is a likelihood of underreported risk factors related to birth defects, such as maternal smoking and environmental exposure during pregnancy, owing to limited data $[35,36]$.

\section{Conclusion}

In conclusion, despite a relative low prevalence of CAKUTs in our study, the rising trend in prevalence merits further attention. Routine screening of CAKUTs should be performed to identify congenital malformations, particularly abnormalities of the cardiovascular system. Once the diagnosis of CAKUTs is made, a complete assessment of coexisting anomalies and suggestions for postnatal care should be provided.

\section{Abbreviations}

CAKUTs: Congenital anomalies of the kidney and urinary tract; $\mathrm{Cl}$ : Confidence interval; CT: Computed tomography; ICD: International Statistical Classification of Diseases; MRI: Magnetic resonance imaging; OR: Odds ratio

\section{Acknowledgments}

We thank the staff of the provincial birth defect surveillance hospitals and all medical workers in the 91 surveillance hospitals. We also thank the Health and Family Planning Commission of Zhejiang Province. In addition, we thank Analisa Avila, ELS, of Liwen Bianji, Edanz Group China (www.liwenbianji.cn/ ac), for editing the English text of a draft of this manuscript.

\section{Funding}

The study was supported by the Health and Family Planning Commission of Zhejiang Province (number 2018268607). This work was also funded by Research on the Application of Public Projects in the Zhejiang Science and Technology Department (2017C22003).
Availability of data and materials

The datasets for the current study are not publicly available but are available upon reasonable request by emailing the corresponding author.

\section{Authors' contributions}

Z-yL conceived the study and drafted the manuscript. Y-mC, L-qQ, and D-qC conceived the study and provided technical assistance. J-yX performed data collection and statistical analysis. $\mathrm{C}-\mathrm{gH}$ conceived the study and revised the article. X-hZ was responsible for birth defect surveillance in Zhejiang Province, participated in planning, and performed statistical analysis. All authors read and approved the final manuscript.

\section{Ethics approval and consent to participate}

The Committee for Research Ethics at Zhejiang Provincial Center for Disease Control and Prevention approved the study (number: 2018KY036). All information was confidential.

\section{Consent for publication}

All parents or caregivers provided their informed consent to participate in the study.

\section{Competing interests}

The authors declare that they have no competing interests.

\section{Publisher's Note}

Springer Nature remains neutral with regard to jurisdictional claims in published maps and institutional affiliations.

\section{Author details}

'Department of Urology, The Second Affiliated Hospital, Zhejiang University School of Medicine, 88 Jiefang Road, Hangzhou, Zhejiang Province 310006, People's Republic of China. ${ }^{2}$ Department of Obstetrics, Women's Hospital, Zhejiang University School of Medicine, No.1 Xueshi Road, Hangzhou, Zhejiang Province 310006, People's Republic of China. ${ }^{3}$ Department of Women's Health, Women's Hospital, Zhejiang University School of Medicine, No.1 Xueshi Road, Hangzhou, Zhejiang Province 310006, People's Republic of China. ${ }^{4}$ Zhejiang Provincial Center for Disease Control and Prevention, 3399 Binsheng road, Hangzhou, People's Republic of China.

Received: 15 June 2018 Accepted: 29 March 2019

Published online: 18 April 2019

\section{References}

1. Postoev VA, Grjibovski AM, Kovalenko AA, Anda EE, Nieboer E, Odland J $\varnothing$. Congenital anomalies of the kidney and the urinary tract: A Murmansk County birth registry study. Birth Defects Res A Clin Mol Teratol. 2016;106(3): 185-93.

2. Bondagji NS. Antenatal diagnosis, prevalence and outcome of congenital anomalies of the kidney and urinary tract in Saudi Arabia. Urol Ann. 2014; 6(1):36-40.

3. Andrés-Jensen L, Jørgensen FS, Thorup J, Flachs J, Madsen JL, Maroun LL, et al. The outcome of antenatal ultrasound diagnosed anomalies of the kidney and urinary tract in a large Danish birth cohort. Arch Dis Child. 2016;101(9): 819-24.

4. Tain $Y L$, Luh $H$, Lin CY, Hsu CN. Incidence and risks of congenital anomalies of kidney and urinary tract in newborns: A population-based case-control study in Taiwan. Medicine (Baltimore). 2016:95(5):e2659.

5. Laurichesse Delmas H, Kohler M, Doray B, Lémery D, Francannet C, Quistrebert J, et al. Congenital unilateral renal agenesis: prevalence, prenatal diagnosis, associated anomalies. Data from two birth-defect registries. Birth Defects Res. 2017;109(15):1204-11.

6. Danziger P, Berman DR, Luckritz K, Arbour K, Laventhal N. Severe congenital anomalies of the kidney and urinary tract: epidemiology can inform ethical decision-making. J Perinatol. 2016;36(11):954-9.

7. Nef S, Neuhaus TJ, Spartà G, Weitz M, Buder K, Wisser J, et al. Outcome after prenatal diagnosis of congenital anomalies of the kidney and urinary tract. Eur J Pediatr. 2016;175(5):667-76.

8. Rosenblum S, Pal A, Reidy K. Renal development in the fetus and premature infant. Semin Fetal Neonatal Med. 2017;22(2):58-66. 
9. Hattori M, Sako M, Kaneko T, Ashida A, Matsunaga A, Igarashi T, et al. Endstage renal disease in Japanese children: a nationwide survey during 20062011. Clin Exp Nephrol. 2015;19(5):933-8.

10. Marzuillo P, Guarino S, Grandone A, Di Somma A, Della Vecchia N, Esposito $T$, et al. Outcomes of a cohort of prenatally diagnosed and early-enrolled patients with congenital solitary functioning kidney. J Urol. 2017;198(5): 1153-8

11. Stoll C, Dott B, Alembik Y, Roth MP. Associated nonurinary congenital anomalies among infants with congenital anomalies of kidney and urinary tract (CAKUT). Eur J Med Genet. 2014;57(7):322-8.

12. Ramanathan S, Kumar D, Khanna M, Al Heidous M, Sheikh A, Virmani V, et al. Multi-modality imaging review of congenital abnormalities of kidney and upper urinary tract. World J Radiol. 2016;8(2):132-41.

13. Dias T, Sairam S, Kumarasiri S. Ultrasound diagnosis of fetal renal abnormalities. Best Pract Res Clin Obstet Gynaecol. 2014;28(3):403-15.

14. Capone VP, Morello W, Taroni F, Montini G. Genetics of congenital anomalies of the kidney and urinary tract: the current state of play. Int J Mol Sci. 2017;18(4):pii: E796

15. Lei TY, Fu F, Li R, Wang D, Wang RY, Jing XY, et al. Whole-exome sequencing for prenatal diagnosis of fetuses with congenital anomalies of the kidney and urinary tract. Nephrol Dial Transplant. 2017;32(10):1665-75.

16. Miao Q, Shen Q, Xu H, Sun L, Tang X, Fang X, et al. Etiological analysis of 264 cases with chronic kidney disease stage 2 to 5 in children. Zhonghua Er Ke Za Zhi. 2015;53(9):665-9 [Article in Chinese].

17. Jiang $Y$, Shen $Y$, Lau KK. Survey of chronic haemodialysis in children between 2007 and 2012 in China. Nephrology (Carlton). 2014 Jul;19(7):375-8.

18. Data from: http://www.eurocat-network.eu/accessprevalencedata/ prevalencetables.

19. Xie $D$, Yang $T$, Liu Z, Wang $H$. Epidemiology of birth defects based on a birth defect surveillance system from 2005 to 2014 in Hunan Province, China. PLoS One. 2016;11(1):e0147280.

20. Lamichhane DK, Leem JH, Park M, Kim JA, Kim HC, Kim JH, et al. Increased prevalence of some birth defects in Korea, 2009-2010. BMC Pregnancy Childbirth. 2016;16:61.

21. Cambra K, Ibañez B, Urzelai D, Portillo I, Montoya I, Esnaola S, et al. Trends in the prevalences of congenital anomalies and age at motherhood in a southern European region: a population-based study. BMJ Open. 2014;4(3): e004244.

22. Bakker MK, van Kammen JEH, Fleurke-Rozema H, Streefland E, Gracchi V, Bilardo CM, et al. Prenatal diagnosis of urinary tract anomalies, a cohort study in the northern Netherlands. Prenat Diagn. 2018 Jan;38(2):130-4.

23. Morris JK, Springett AL, Greenlees R, Loane M, Addor MC, Arriola L, et al. Trends in congenital anomalies in Europe from 1980 to 2012. PLoS One. 2018 Apr 5;13(4):e0194986.

24. dos Santos Junior AC, de Miranda DM, Simões e Silva AC. Congenital anomalies of the kidney and urinary tract: an embryogenetic review. Birth Defects Res C Embryo Today. 2014;102(4):374-81.

25. Ristoska-Bojkovska N. Congenital anomalies of the kidney and urinary tract (CAKUT). Prilozi. 2017;38(1):59-62.

26. Groen In 't Woud S, Renkema KY, Schreuder MF, Wijers CH, van der Zanden $L F$, Knoers NV, et al. Maternal risk factors involved in specific congenital anomalies of the kidney and urinary tract: A case-control study. Birth Defects Res A Clin Mol Teratol. 2016;106(7):596-603.

27. Macumber I, Schwartz S, Leca N. Maternal obesity is associated with congenital anomalies of the kidney and urinary tract in offspring. Pediatr Nephrol. 2017;32(4):635-42.

28. Wu W, Hu L, Oiu L, Oiu L, Hu C. Analysis of the incidence and perinatal outcomes of multiple births in Zhejiang Province from 2008 to 2013. Zhonghua Yu Fang Yi Xue Za Zhi. 2015:49(3):265-8 [Article in Chinese].

29. Liberman RF, Getz KD, Heinke D, Luke B, Stern JE, Declercq ER, et al. Assisted reproductive technology and birth defects: effects of subfertility and multiple births. Birth Defects Res. 2017;109(14):1144-53.

30. Hoorsan H, Mirmiran P, Chaichian S, Moradi Y, Hoorsan R, Jesmi F. Congenital malformations in infants of mothers undergoing assisted reproductive technologies: A systematic review and meta-analysis study. J Prev Med Public Health. 2017:50(6):347-60.

31. Dawson AL, Tinker SC, Jamieson DJ, Hobbs CA, Berry RJ, Rasmussen SA, et al. Twinning and major birth defects, National Birth Defects Prevention Study, 1997-2007. J Epidemiol Community Health. 2016;70(11):1114-21.
32. Liu QG, Sun J, Xiao XW, Song GR. Birth defects data from surveillance hospitals in Dalian city, China, 2006-2010. J Matern Fetal Neonatal Med. 2016;29(22):3615-21.

33. Stoll C, Dott B, Alembik Y, Roth MP. Associated noncardiac congenital anomalies among cases with congenital heart defects. Eur J Med Genet. 2015:58(2):75-85

34. A Correia JD, da Rosa EB, Silveira DB, Grapiglia CG, Canabarro ST, Waterkemper R, Zen PR, Rosa RF. Major Extracardic malformations among patients with congenital heart defects. Int J Cardiol 20161;214:154-156.

35. Taye M, Afework M, Fantaye W, Diro E, Worku A. Factors associated with congenital anomalies in Addis Ababa and the Amhara region, Ethiopia: a case-control study. BMC Pediatr. 2018;18(1):142.

36. Liang Z, Wu L, Fan L, Zhao Q. Ambient air pollution and birth defects in Haikou city, Hainan province. BMC Pediatr. 2014;14:283.
Ready to submit your research? Choose BMC and benefit from:

- fast, convenient online submission

- thorough peer review by experienced researchers in your field

- rapid publication on acceptance

- support for research data, including large and complex data types

- gold Open Access which fosters wider collaboration and increased citations

- maximum visibility for your research: over $100 \mathrm{M}$ website views per year

At $\mathrm{BMC}$, research is always in progress.

Learn more biomedcentral.com/submissions 